\title{
Critical Literacy in the Primary Classroom
}

\author{
JULIE MacDONALD \\ Waterloo Region District School Board \\ MELISSA HALVORSEN \\ Waterloo Region District School Board \\ CAROL WILCOX \\ Waterloo Region District School Board
}

\begin{abstract}
The action research project entailed the development of critical literacy lessons designed for the primary classroom. Data was collected to determine the students' knowledge of voice/voiceless, point of view, and author's message. Results indicated that primary children are able to successfully respond critically to texts. As critical literacy is a venue for higher level thinking, the students were able to deepen their understanding of text.
\end{abstract}

\section{Introduction}

Our students were already using a wide variety of reading strategies (visualizing, making connections, asking questions, inferring, and synthesizing) to expand their comprehension of text and we wanted to explore possible next steps for instruction. We decided that the most valuable next steps for our students would be to provide instruction in critical literacy skills. We discovered through our professional readings that there appears to be more of an emphasis on critical literacy for older students. We agree with Leland, Harste, and Huber (2004) who state that "what is missing . . . is the involvement of young learners in deeper processes of critique and analysis . . . children who experience a critical approach to literacy learn to 'read between the lines' and generate alternative explanations regarding the author's intent" (p. 259). It was felt that our primary students would benefit from critical literacy instruction in order to develop the ability to think critically and make informed decisions about texts. The team viewed critical literacy as a method that enabled students to think more deeply about texts and empowered them 
to reflect and move beyond passively accepting the author's message. According to McLaughlin and DeVoogd (2004), there are four principles of critical literacy. First, critical literacy focuses on the power relationship between author and reader and assists the reader in understanding that he/she may reflect upon and decide for themselves if they accept or reject the author's perspective. Second, the reader may question and look for an alternative perspective. Third, critical literacy strategies are adaptable and may vary according to context and, finally, critical literacy challenges the traditional interpretation of texts by considering it from different perspectives.

We feel it is important to teach critical literacy to students so they can develop a deeper understanding of the many texts that surround them in the world. Our students need to be given the tools necessary to think critically about what they read in order to question, analyze, and recognize underlining biases in order to make informed observations and conclusions. We want them to be able to view the world with open and questioning eyes. Critical literacy is a lifelong skill that will allow students to make informed decisions that will have an impact throughout their lives.

\section{Project Overview}

To begin our project we decided upon the following research question: How will instruction in critical literacy enable primary students to respond critically to text? We started with a pre-test that assessed students' understanding of voice, the voiceless, the voiceless perspective, and the author's message. The book Swimmy by Leo Lionni was used for the pretest. We used the following definitions for the purpose of this project: voice refers to the character whose message is most prominently (usually most positively) portrayed, and voiceless refers to the character whose message is marginalized. The voiceless perspective was an opportunity for students to indicate what that character might say, while the author's message was what meanings and values does the text seem to convey. Two Grade One classes and one Grade Three class participated in this action research project.

Several critical literacy lessons were planned and implemented. A variety of different texts were used for students to discuss the following questions: whose voice is heard; whose 
voice is missing; what would that character say; what does the author want you to think; and what do you think? We used a variety of teaching strategies to promote critical literacy in our classrooms. Among the valuable teaching strategies was the anticipation strategy. An anticipation statement is a simple statement on a specific point (e.g. Jack and the Beanstalk: Jack is a hero) that promotes awareness and discussion and sets the purpose for reading. The strategy of "sitting in the hot seat" involves the teacher waving a magic wand to turn the student into a character from the story. Other students ask the student as the character to explain their viewpoint from the story. The strategy of "vote with your feet" asked students to express their opinion by walking to a designated area that represented a particular viewpoint of the text. Students would talk to someone who voted the same way to share ideas and afterwards would talk to someone with an opposing idea to explain their thinking and to listen to the rationale of the opposing viewpoint. An extension was to ask students if their opinion had changed as a result of the discussion. Students would vote one last time with their feet.

Several conversations were audio-taped and conversations were scribed for anecdotal evidence of progress. Teachers wrote in their reflection journals on a regular basis to assess learning strategies, challenges, successes, and next steps. In April, a final assessment task was assigned to students which used the same text and graphic organizer as the pre-test. Teachers reread the book Swimmy by Leo Lionni and students used the same graphic organizer as the pretest to respond to the text.

\section{Data Collection}

Three forms of data were collected for this project. For the pre- and post-assessment task, the graphic organizer recorded student understanding of voice, voiceless, voiceless perspective, and author's message. Teachers scribed for their students as needed so that answers were not limited as a result of limited writing ability. Class discussions based on critical literacy conversations were audio-taped and then transcribed for analysis. Teachers kept reflection journals and recorded their thoughts regarding lessons and student progress in reflective journals throughout the project. 


\section{Data Analysis}

A rubric was designed for the pre- and post-assessment task to assess students' ability to identify and understand the voice and the voiceless as well as the author's message. The rubric was developed by examining and discussing a rubric used by Washington State University that contained seven criteria for rating critical and integrative thinking (Center for Teaching, Learning, \& Technology 2006). Criteria that were applicable to the primary grades were extracted and used in making the rubric for this study. The criteria used for the primary rubric were also linked to criteria found in Critical Literacy: Enhancing Students' Comprehension of Text (McLaughlin \& DeVoogd, 2004). Teachers moderated together to agree on grading for the students from each class. This was done by looking at each piece of student work together, having a brief discussion about it, and then coming to a consensus on a level for it. Using the four key assessment categories from the rubric, teachers also searched the transcribed notes looking for patterns, for the beginning (November), middle (February), and end of the process (April). Teachers reread their journals, as well as colleagues' journals, highlighting themes that arose. Quotes from teacher journals were recorded and divided into beginning (November), middle of process (February), and end of the process (April).

\section{Principle Findings}

In the pre-and post-tests, $94 \%$ of students were able to correctly identify a key voice/perspective that was heard in the story. In the pre-test, $50 \%$ of students were able to correctly identify the voiceless in the story. In the post-test, $81 \%$ of students were able to correctly identify the voiceless in the story. Fifty-six percent of students demonstrated growth in the ability to express a voiceless character's perspective. Of pre-test level 2 student responses, $80 \%$ increased to a level 3 response or above. One hundred percent of level 3 or 4 responses went down. Regarding the author's message, $81 \%$ of students moved up an assessment category. Of Level One pre-test student responses, $83 \%$ of students showed improvement with 33\% moving to a Level Two, 25\% moving to a Level Three, and 25\% moving to a Level Four.

The audio-taped conversations indicate students initially had difficulty with critical 
literacy concepts, and responses were literal and brief. Misconceptions about the concept of voice and voiceless were apparent. Midway through the project, it was noted that some students were demonstrating a greater understanding of voice, voiceless, and author's message. Some students were increasingly able to support their opinions with evidence and more detailed responses. At the end of the project, many students were able to clearly identify voice, voiceless, and author's message with logical, supporting evidence. There was evidence of students demonstrating an increasing ability to express their thoughts through both agreeing and disagreeing with their classmates and giving reasons why.

\section{Teacher Reflection}

Teacher reflection comments showed early concerns about the ability of students to grasp concepts, while later comments showed excitement about student progress in better implementing critical literacy skills. Early teacher comments reflected concerns and some frustrations regarding the amount of literal, off topic, and occasionally silly responses. All teachers commented on the breadth of critical literacy (e.g., gender, class, social issues) and the necessity to narrow it down in order to make it attainable for the students. In order to do this, we provided students with initial guidance on how to express their opinions, encouraging them to use a sentence starter and give proof for their opinions (e.g., "I think . . because . . ”). As students learned that their opinions mattered, they felt validated and class conversations became more student led. The class also sat in a circle so that all students' facial expressions could be easily seen and there would be no difficulties hearing their responses. We also began using a learning wall that demonstrated the progression of student thinking and contained anchor charts (e.g., "Readers have Power"), anticipation statements and student responses, and photocopies of book covers that were read. Midway through the project, we observed that some students were beginning to provide more in-depth responses by providing more evidence for their thinking. At the end of the project, teacher journals were more positive and demonstrated growing excitement about student progress. Teachers observed more on-task behaviour, greater active engagement, evidence-based responses, and more dialogue between students. 


\section{Conclusions}

Based on the data, it was found that instruction in critical literacy enables primary students to respond critically to text. An increased number of students were able to perform at the provincial standard of level 3 and 4. It was pleasing to see an increase in the number of students who were able to identify the voiceless, which was considered to be a difficult concept to understand. Another challenging area, identifying and explaining the author's message, also showed significant growth, with students supporting their opinions with evidence that demonstrated higher-level thinking. It was surprising and also gratifying to see tremendous growth in the students' ability to converse with their classmates, whether it was to agree or disagree with them. Finally, it was noticed that students felt empowered and enjoyed stating their opinions and participating in discussions.

\section{Implications for Educators}

In regards to student learning, there were three areas in which implications were identified for educators. Critical literacy lessons gave students a sense of empowerment and critical literacy discussions provided an opportunity for students to speak up, voice their own opinion and be accepted for their ideas. Teachers were excited by the dialogue between students that had not been seen previously. Students were listening to peers' ideas and felt free to agree or disagree. Usually, the exchange of ideas in a classroom occurs between teacher-student and student-teacher; however, this shifted and conversation became student-student centred on a more regular basis. Finally, as critical literacy is a venue for higher-level thinking, the students did develop higher-level thinking skills and deepened their understanding of texts. Students clearly considered texts in new ways and learned to back up their ideas with evidence. Teachers also found students were actively engaged in the learning process and that critical literacy discussions had children discussing books for extended periods of time.

We identified five areas of growth for us as professionals. First, through working on the Teachers Learning Together (TLT) Action Research project, we were able to develop a 
constructive Professional Learning Community. The opportunity to work together to share information and dialogue about best practice allowed us to become more effective teachers. Secondly, we were able to further develop our expertise in higher level thinking. The way we think, plan, and implement our programs has changed since the implementation of this project. We now look at text more critically ourselves and can provide rich opportunities for our students to consider text in new ways. Thirdly, we learned new effective teaching strategies that can be used across the curriculum. One favourite strategy was the anticipation statement that helped set the stage for discussion. Next, we felt great satisfaction in the fact that we enhanced the learning of our students and ourselves. We have a great sense of achievement about the positive results for our students in terms of empowering them to think more critically and demonstrate more confidence expressing their own ideas. Finally, we learned about the benefits of teachers participating in their own Action Research. We enjoyed the opportunity to choose a topic of interest for us, implement new information in our own classrooms, and collect and analyze data to prove or refute the effectiveness of such implementation.

\section{Acknowledgement}

This report describes an action research project sponsored by the Elementary Teachers' Federation of Ontario. The teacher team involved was mentored by Dr. Candace Figg and Dr. Kamini Jaipal-Jamani from the Faculty of Education Department at Brock University.

\section{References}

Center for Teaching, Learning, \& Technology. (2006). Guide to rating critical \& integrative thinking. Washington State University. Retrieved on January 14, 2008 from https://my.wsu.edu/portal/page?_pageid $=177,276578 \&$ dad=portal\&_schema=PORTAL

Leland, C. H., Harste, J. C., \& Huber, K. R. (2005). Out of the box: Critical literacy in a firstgrade classroom. Language Arts, 82(4), 257-268.

McLaughlin, M., \& DeVoogd, G. L. (2004). Critical literacy: Enhancing students' comprehension of text. Toronto: Scholastic Inc. 